\title{
Effect of cytochrome P450 and aldo-keto reductase inhibitors on progesterone inactivation in primary bovine hepatic cell cultures ${ }^{1}$
}

\author{
C. O. Lemley and M. E. Wilson ${ }^{2}$ \\ Division of Animal and Nutritional Sciences, Davis College of Agriculture, Natural Resources and Design, West Virginia University, \\ Morgantown 26506
}

\begin{abstract}
Progesterone is required for maintenance of pregnancy, and peripheral concentrations of progesterone are affected by both production and inactivation. Hepatic cytochrome P450 (EC 1.14.14.1) and aldo-keto reductase (EC 1.1.1.145-151) enzymes play a pivotal role in the first step of steroid inactivation, which involves the addition of hydroxyl groups to various sites of the cyclopentanoperhydrophenanthrene nucleus. The current objective was to discern the proportional involvement of hepatic progesterone inactivating enzymes on progesterone decay using specific enzyme inhibitors. Ticlopidine, diltiazem, curcumin, dicumarol, and naproxen were used because of their selective inhibition of cytochrome P450s, aldo-keto reductases, and glucuronosyltransferases. Liver biopsies were collected from 6 lactating Holstein dairy cows, and cells were dissociated using a nonperfusion technique. Confluent wells were preincubated for $4 \mathrm{~h}$ with enzyme inhibitor and then challenged with progesterone for $1 \mathrm{~h}$. Cell viability was unaffected by inhibitor treatment and averaged $84 \pm 1 \%$. In control wells, $50 \%$ of the progesterone had been inactivated after a 1-h challenge with 5 $\mathrm{ng} / \mathrm{mL}$ of progesterone. Preincubation with curcumin, ticlopidine, or naproxen caused the greatest reduction in progesterone inactivation compared with controls and averaged 77,39 , or $37 \%$, respectively. Hydroxylation of 4-nitrophenol to 4-nitrocatechol in intact cells was inhibited by approximately $65 \%$ after treatment with curcumin or ticlopidine. Glucuronidation of phenol red or 4-nitrocatechol in intact cells was inhibited by treatment with curcumin, dicumarol, or naproxen. In cytoplasmic preparations, aldo-keto reductase $1 \mathrm{C}$ activity was inhibited by curcumin, dicumarol, or naproxen

\footnotetext{
Received February 11, 2010.

Accepted June 7, 2010.

${ }^{1}$ This work is published with the approval of the Director of West

${ }^{2}$ Corresponding author: mwilso25@wvu.edu
} Virginia Agriculture and Forestry Experiment Station as scientific paper 3073. This project was supported by National Research Initiative Competitive Grant no. 2008-35203-04503 from the USDA Cooperative State Research, Education, and Extension Service and Hatch project 468 (NE 1007).
\end{abstract}

treatment. Microsomal cytochrome P450 2C activity was inhibited by treatment with curcumin or ticlopidine, whereas cytochrome P450 3A activity was inhibited by treatment with curcumin or diltiazem. The contribution of cytochrome P450 2C and cytochrome P450 3A enzymes to progesterone inactivation in bovine hepatic cell cultures was 40 and $15 \%$, respectively. Depending on the inhibitor used, it would appear that the aldoketo reductase enzymes contribute approximately $40 \%$ to the observed progesterone inactivation, although a portion of this inactivation may be attributed to the loss of glucuronosyltransferase activity. Future work focusing on decreasing the activity of these enzymes in vivo could lead to an increase in the bioavailability of progesterone.

Key words: cytochrome P450, aldo-keto reductase, progesterone decay, hepatic cell isolation

\section{INTRODUCTION}

Several reviews have addressed the issue of low fertility in the lactating dairy cow, and an increasing number of observations have associated metabolic demand, as a result of continued selection for milk yield, with altered hormonal profiles and fertility (Chagas et al., 2007; Leroy et al., 2008). Increased rates of steroid inactivation may contribute to lower concentrations of progesterone in the pregnant lactating dairy cow (Rhinehart et al., 2009). Independent reports have shown a positive relationship between the metabolic clearance rate of progesterone and liver blood flow in both the sheep and dairy cow (Parr et al., 1993; Sangsritavong et al., 2002). Recently, our laboratory observed a longer half-life of progesterone in dairy cows fed an insulin-stimulating diet that decreased the activity of cytochrome P450 (CYP) 2C and CYP 3A (Lemley et al., 2010). In the pig, the metabolic clearance rate of progesterone was not correlated with CYP content in the liver after altering feed intake; however, total CYP content was positively correlated with the rate of progesterone inactivation in vitro (Miller et al., 1999). Furthermore, induction of mixed function monooxygenases (CYP superfamily) using phenobarbital can alter the rate of 


\section{Progesterone}
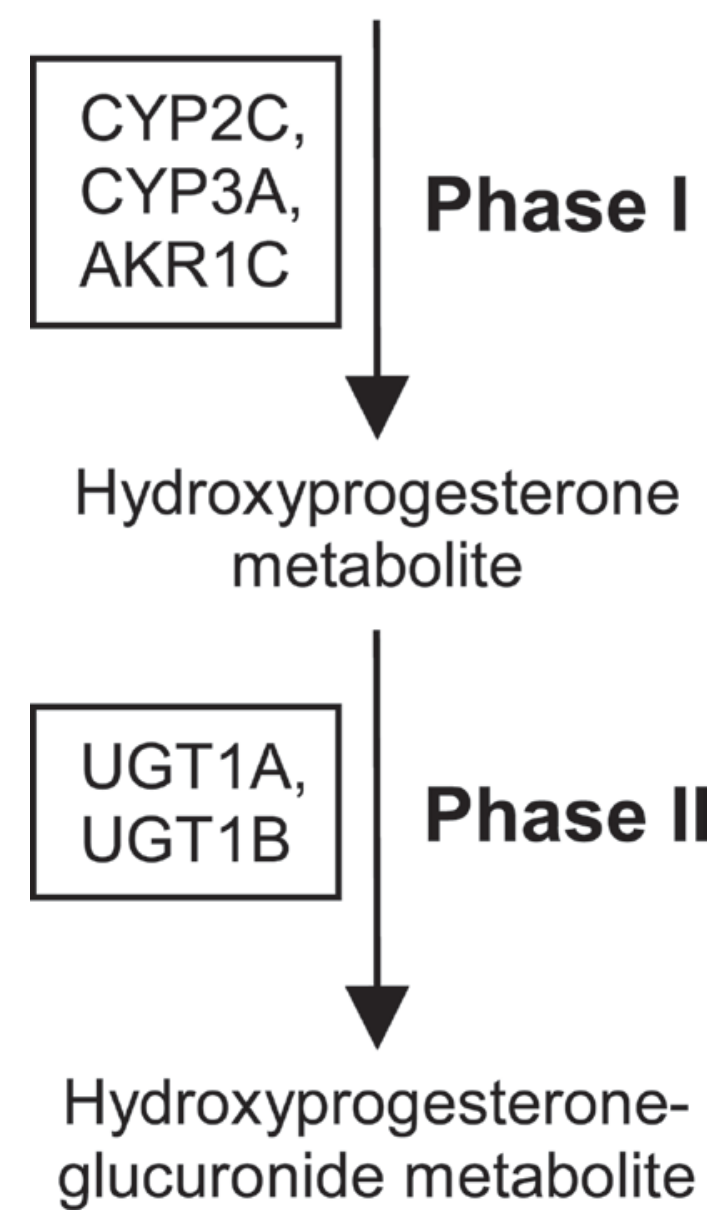

Figure 1. Progesterone inactivation in hepatocytes. Enzymes for phase I and phase II of progesterone inactivation are depicted in boxes. Phase I enzymes are involved in the addition of hydroxyl groups to the steroid nucleus, and phase II enzymes are involved in conjugating the hydroxyprogesterone metabolite with glucuronic acid. CYP2C $=$ cytochrome P450 2C; CYP3A = cytochrome P450 3A; ARK1C = aldo-keto reductase $1 \mathrm{C}$ subfamily; UGT1A = uridine diphosphateglucuronosyltransferase 1A; UGT1B = uridine diphosphate-glucuronosyltransferase $1 \mathrm{~B}$.

steroid clearance in the barrow and gilt (Thomford and Dziuk, 1986).

Both phase I and phase II steroid-inactivating enzymes are involved in hepatic progesterone clearance; a general depiction of progesterone inactivation is shown in Figure 1. The CYP superfamily (located in the endoplasmic reticulum or microsomal cellular fractions) of enzymes are involved in several pathways including endogenous vitamin $\mathrm{D}_{3}$ activation, metabolism of cholesterol to bile acids, metabolism of all major classes of steroid hormones (Waxman et al., 1991), and xenobiotic metabolism (Anzenbacher and Anzenbacherova, 2001). In sheep liver, CYP2C and CYP3A metabolized progesterone to 21-hydroxyprogesterone (deoxycorticoster- one) and 6 3 -hydroxyprogesterone, respectively (Murray, 1991, 1992). The aldo-keto reductase (AKR) enzymes are involved in the reduction of glucose, prostaglandin metabolism, generation of bile acids, and reduction of steroids containing aldehyde or ketone groups (Penning et al., 2000; Barski et al., 2008; Kabututu et al., 2009). The AKR1C subfamily converts progesterone to $3 \alpha$-hydroxyprogesterone or $20 \alpha$-hydroxyprogesterone in humans and rodents (Penning et al., 2000). Phase II of steroid inactivation, generation of a more hydrophilic pregnanediol metabolite, involves uridine diphosphate-glucuronosyltransferase (UGT) enzymes, which conjugate the inactive hydroxysteroid metabolites with glucuronic acid. The enzymes UGT1A and UGT2B have been implicated in glucuronidation of hydroxylated derivatives of C18, C19, and C21 steroids (Bowalgaha et al., 2007).

These previous studies in sheep, rodents, and humans cannot be extrapolated to the lactating dairy cow. Moreover, it does not seem reasonable to estimate the relative contributions of metabolizing enzymes to the rate of progesterone inactivation in cytoplasmic versus microsomal protein fractions from independent reports. Despite numerous reports implicating low progesterone in the observed low fertility in dairy cows, the contributions of CYP, AKR, and UGT enzymes in the dairy cow have not garnered much attention. In addition, we felt it was necessary to study hepatic cultures from early-lactating dairy cows because of the metabolic differences observed in lactating versus nonlactating sheep hepatocyte cultures (Emmison et al., 1991). The objectives of the current experiment were to determine the contributions of steroid-inactivating enzymes (CYP, AKR, and UGT) to total progesterone decay in primary hepatic cell cultures from early-lactation dairy cows using specific enzyme inhibitors.

\section{MATERIALS AND METHODS}

\section{Tissue Collection}

In a preliminary experiment, liver tissue was collected from animals undergoing euthanasia for an independent project (2 pigs and 2 dairy cows) and used to optimize cell dissociation techniques, progesterone inactivation, and cell viability after enzyme inhibitor challenges, which are described below. Following the preliminary experiments, liver biopsies were collected from 6 lactating Holstein dairy cows housed at the West Virginia University Animal Sciences Farm (Morgantown, WV), averaging $54 \pm 4$ DIM and $47.0 \pm$ $2.6 \mathrm{~kg}$ of milk production per day. Liver biopsies were taken approximately $4 \mathrm{~h}$ after the scheduled $0800 \mathrm{~h}$ milking and feeding following the methods of Lemley et 
Table 1. Liver biopsies from 6 lactating dairy cows used for cell culture experiments ${ }^{1}$

\begin{tabular}{lccccc}
\hline Item & DIM & $\begin{array}{c}\text { Milk } \\
\text { yield, kg }\end{array}$ & $\begin{array}{c}\text { Liver } \\
\text { sample, }\end{array}$ & $\begin{array}{c}\text { Cell yield, } \\
10^{6} \text { cells }\end{array}$ & $\begin{array}{c}\text { Cell } \\
\text { viability, \% }\end{array}$ \\
\hline Cow identification no. & & & & & \\
273 & 67 & 46.4 & 0.92 & 36 & 85 \\
285 & 57 & 54.5 & 0.94 & 75 & 91 \\
300 & 41 & 50.5 & 1.31 & 37 & 71 \\
305 & 46 & 51.8 & 1.21 & 25 & 70 \\
314 & 54 & 39.5 & 0.79 & 28 & 89 \\
325 & 56 & 39.1 & 1.01 & 48 & 4 \\
Mean & 54 & 47.0 & 1.03 & 42 & 7 \\
SEM & 4 & 2.6 & 0.08 & & 43 \\
\hline
\end{tabular}

${ }^{1}$ Stage of lactation, milk yield, and liver biopsy weight for individual dairy cows, and cell yield and viability following tissue dissociation using a nonperfusion technique.

al. (2010). Liver samples were blotted on sterile gauze to remove any excess blood, immersed in HEPES buffered salt solution (HBSS; $10 \mathrm{~m} M$ HEPES, $136 \mathrm{mM}$ sodium chloride, $5 \mathrm{mM}$ potassium chloride, and $27 \mathrm{mM}$ glucose; $\mathrm{pH}=7.4$ ) containing $0.05 \mathrm{mM}$ ethylene glycol tetraacetic acid, and transported to the laboratory on ice within $1 \mathrm{~h}$ of collection. Animal care and use were according to a protocol approved by the West Virginia University Animal Care and Use Committee (ACUC \#07-0503).

\section{Cell Dissociation}

Cells were dissociated using a nonperfusion technique (modified from Spotorno et al., 2006). Liver tissue was finely minced with a scalpel blade and washed with HBSS containing $0.05 \mathrm{mM}$ ethylene glycol tetraacetic acid by centrifugation at $50 \times g$ for $3 \mathrm{~min}$. Tissue was then washed with HBSS by centrifugation at $50 \times g$ for $3 \mathrm{~min}$ and suspended in $150 \mathrm{~mL}$ of HBSS containing $1 \mathrm{~m} M$ calcium chloride and $150 \mathrm{U} / \mathrm{mL}$ of type $1 \mathrm{~A}$ collagenase (Sigma Chemical Co., St Louis, MO). Tissue was incubated with collagenase for $45 \mathrm{~min}$ at $37^{\circ} \mathrm{C}$ with gentle shaking. After the 45-min incubation, $50 \mathrm{~mL}$ of Dulbecco's modified Eagle's medium/Ham's nutrient mixture F-12 (D-MEM/F-12; 1:1 ratio; ATCC, Manassas, VA) containing $10 \%$ fetal bovine serum (Thermo Fisher Scientifics, Waltham, MA) was added to the solution. The cell and tissue suspension was then processed through 425-, 212-, and 106- $\mu \mathrm{m}$ stainless steel sieves. Cell suspensions were centrifuged at $100 \times$ $g$ for 5 min and pellets were washed twice with Hanks' buffered salt solution (Hanks'; $5.3 \mathrm{mM}$ potassium chloride, $0.4 \mathrm{~m} M$ monobasic potassium phosphate, $4.2 \mathrm{mM}$ sodium bicarbonate, $137.9 \mathrm{mM}$ sodium chloride, 0.3 $\mathrm{m} M$ dibasic sodium phosphate, and $5.6 \mathrm{~m} M$ glucose; $\mathrm{pH}=7.4$; Sigma Chemical Co.). Cell viability and yield (Table 1) were determined using trypan blue stain (Invitrogen, Carlsbad, CA) and a Bright-line hemacytometer (Hausser Scientific, Horsham, PA).

\section{Cell Culture}

Hepatic cells were plated on 24-well tissue culture treated polystyrene plates (Becton Dickinson Labware, Franklin Lakes, NJ) at a density of 0.8 to $1.2 \times 10^{6}$ viable cells/well in growth media. Growth media contained DMEM/F-12 media with the addition of $10 \%$ fetal bovine serum, $500 \mathrm{IU} / \mathrm{mL}$ of penicillin (Invitrogen), $500 \mu \mathrm{g} /$ $\mathrm{mL}$ of streptomycin (Invitrogen), $10 \mathrm{n} M$ insulin (Sigma Chemical Co.), $1 \mathrm{n} M$ glucagon (Sigma Chemical Co.), $10 \mathrm{ng} / \mathrm{mL}$ of epidermal growth factor (Invitrogen), and $10 \mathrm{n} M$ dexamethasone (Thermo Fisher Scientifics) sterile filtered with $0.22-\mu \mathrm{m}$ polyethersulfone filters (Fisher Scientific, Wilkes Barre, PA). Growth media was replaced every $24 \mathrm{~h}$ and cultures were maintained in an incubator set at $37^{\circ} \mathrm{C}$ under a humidified gas mixture of 95\% air and 5\% carbon dioxide.

\section{Fluorescence Staining and Image Analysis}

Cells were cultured on glass coverslips coated in poly L-lysine (Sigma) and allowed to reach 80 to $90 \%$ confluence before preparing coverslips for immunocytochemistry. Growth and morphology remained similar between cells grown on glass coverslips and tissue culture treated polystyrene plates. Cell cultures were exposed to serum-free and phenol red-free D-MEM/F-12 media (Invitrogen) containing $500 \mathrm{IU} / \mathrm{mL}$ of penicillin and $500 \mu \mathrm{g} / \mathrm{mL}$ of streptomycin (serum-free media) $24 \mathrm{~h}$ before staining. Cell cultures were washed with PBS $(\mathrm{pH}=7.3)$ and fixed with buffered neutral formalin (10\%; VWR International, Bridgeport, NJ) for 15 min at $21^{\circ} \mathrm{C}$. Cell cultures were washed with PBS and incubated for 10 min with PBS containing Tween $20(0.3 \%)$. Cells were incubated with blocking buffer (PBS $+0.3 \%$ Tween $20+1 \%$ gelatin) for $30 \mathrm{~min}$ at $21^{\circ} \mathrm{C}$. Primary and secondary antibodies were incubated for $1 \mathrm{~h}$ at $21^{\circ} \mathrm{C}$. Antibodies [mouse monoclonal anti-actin; goat polyclonal anti-mouse IgG conjugated with phycoerythrin (PE); sheep polyclonal anti-bovine 
Table 2. Enzyme inhibitors, phase I or phase II of steroid biotransformation, used for intact cell culture and fractionated tissue experiments ${ }^{1}$

\begin{tabular}{|c|c|c|c|c|}
\hline $\begin{array}{l}\text { Enzyme } \\
\text { inhibitor }\end{array}$ & Phase I & Phase II & $\begin{array}{l}\text { Type of } \\
\text { inhibition }\end{array}$ & Reference \\
\hline Ticlopidine & CYP2C & - & Competitive & Ko et al. (2000) \\
\hline Diltiazem & CYP3A & - & Irreversible & Jones et al. (1999) \\
\hline Curcumin & CYP & UGT & Mixed & Basu et al. (2005); Volak et al. (2008) \\
\hline Dicumarol & — & UGT & Competitive & Segura-Aguilar et al. (1986) \\
\hline Naproxen & AKR & - & - & Yee et al. (2006) \\
\hline
\end{tabular}

${ }^{1} \mathrm{CYP} 2 \mathrm{C}=$ cytochrome $\mathrm{P} 450$ 2C; CYP3A = cytochrome P450 3A; CYP = cytochrome P450; AKR = aldo-keto reductase; $\mathrm{UGT}=$ uridine diphosphate-glucuronosyltransferase.

serum albumin; and rabbit polyclonal anti-sheep $\operatorname{IgG}$ conjugated with fluorescein-5-isothiocyanate (FITC)] were purchased from Abcam Inc. (Cambridge, MA). At the end of the antibody incubations, a subset of the cell cultures were incubated for $1 \mathrm{~min}$ with 0.05 $\mathrm{m} M$ Hoechst 33258 (Sigma Chemical Co.) diluted in automation buffer (138 mM sodium chloride, $20.1 \mathrm{mM}$ Tris hydrochloride, $4.87 \mathrm{mM}$ Tris base). Stained coverslips were mounted with Fluoromount (Sigma Chemical Co.) and cells were visualized using a Nikon Eclipse TE2000-S inverted microscope (Nikon, Tokyo, Japan) equipped with a $100 \mathrm{~W}$ mercury vapor lamp. Ultraviolet, blue, and green filter sets were used to detect Hoechst, rabbit polyclonal anti-sheep IgG conjugated with fluorescein-5-isothiocyanate, and goat polyclonal anti-mouse IgG conjugated with phycoerythrin fluorescence, respectively. Pictures were taken with a $\mathrm{Q}$ Imaging Retiga 2000R camera using Q capture 2.90.1 software (Quantitative Imaging Corporation, Surrey, British Columbia, Canada). Pictures of the fluorescent images were merged using Northern Eclipse software (Empix Imaging Inc., Cheektowaga, NY).

\section{Enzyme Inhibitors}

All inhibitors were purchased from Sigma Chemical Co. (St Louis, MO) and had been previously shown to inhibit CYP, AKR, and UGT enzymes (Table 2). Stock solutions of $0.1 \mathrm{M}$ ticlopidine in methanol, $0.1 \mathrm{M}$ diltiazem in water, $27 \mathrm{~m} M$ curcumin in dimethyl sulfoxide, $4 \mathrm{~m} M$ dicumarol in methanol, and $0.1 M$ naproxen in acetone were prepared. All inhibitors were diluted in 5 $\mathrm{mL}$ of serum-free media to reach final concentrations of $50 \mu M$ ticlopidine, $50 \mu M$ diltiazem, $20 \mu M$ curcumin, $20 \mu M$ dicumarol, and $50 \mu M$ naproxen. Treatments using methanol or acetone as a vehicle were between 0.05 to $0.50 \%$ in the final solution. In the preliminary experiments, vehicle alone did not alter progesterone decay compared with controls, and enzyme activity (CYP2C, CYP3A, and AKR1C) was not affected by vehicle alone for the cell fraction experiments.

\section{Progesterone Inactivation}

Experiments were started once cell cultures reached 80 to $90 \%$ confluence and cells were determined to be metabolically active because of the disappearance of phenol red from the growth media (averaging $14 \pm 2 \mathrm{~d}$ in culture at the time of experimentation). Progesterone inactivation was determined in duplicate (2 wells/ cow) for each of the 6 dairy cows biopsied. The day before experimentation, growth media was replaced with serum-free media (absent of phenol red to remove any confounding effects of phenol red metabolism on progesterone inactivation). An identical plate containing no cells was cultured under the same experimental conditions to ensure progesterone inactivation was cell dependent and not attributable to culture conditions. The media was replaced $24 \mathrm{~h}$ later with serum-free media containing no inhibitor or enzyme inhibitor for $4 \mathrm{~h}$. Following the 4-h enzyme inhibition, media was replaced with serum-free media containing $5 \mathrm{ng} / \mathrm{mL}$ of progesterone with no inhibitor or enzyme inhibitor and incubated for $1 \mathrm{~h}$. A stock solution of $5 \mu \mathrm{g} / \mathrm{mL}$ of progesterone was prepared in ethanol and diluted to 5 $\mathrm{ng} / \mathrm{mL}$ in $5 \mathrm{~mL}$ of serum-free media ( $0.1 \%$ ethanol in final solution). Media from plates containing cells or no cells were analyzed for progesterone concentrations using RIA (Sheffel et al., 1982) with a sensitivity of 100 $\mathrm{pg} / \mathrm{mL}$.

\section{4-Nitrophenol and Phenol Red Metabolism}

Experiments were started once cell cultures reached 80 to $90 \%$ confluence. 4-Nitrophenol and phenol red metabolism was determined in duplicate (2 wells/cow) for each of the 6 dairy cows biopsied. The day before experimentation, growth media was replaced with serum-free media (absent of phenol red to remove any confounding effects of phenol red metabolism on 4-nitrophenol metabolism). The media was replaced $24 \mathrm{~h}$ later with serum-free media containing no inhibitor or enzyme inhibitor for $4 \mathrm{~h}$. The cells were then challenged 
Table 3. Substrates used for enzymatic activity assays in intact cell cultures or fractionated tissue preparations $^{1}$

\begin{tabular}{llll}
\hline $\begin{array}{l}\text { Enzyme } \\
\text { substrate }\end{array}$ & Phase I & Phase II & Reference \\
\hline 4-Nitrophenol & CYP2 & UGT1A & Zerilli et al. (1997); Nakajima et al. (2002) \\
$\begin{array}{l}\text { Phenol red } \\
\text { 1-Acenapthenol }\end{array}$ & AKR1C & UGT1B & $\begin{array}{l}\text { Behnia et al. (2000); Turgeon et al. (2003) } \\
\text { Omeprazole }\end{array}$ \\
Nifedipine & CYP2C & - & Savlík et al. (2007) \\
\hline
\end{tabular}

${ }^{1} \mathrm{CYP} 2=$ cytochrome P450 2; AKR1C = aldo-keto reductase $1 \mathrm{C}$ subfamily; CYP2C = cytochrome P450 2C; CYP3A = cytochrome P450 3A; UGT1A = uridine diphosphate-glucuronosyltransferase 1A; UGT1B = uridine diphosphate-glucuronosyltransferase $1 \mathrm{~B}$.

with serum-free media containing $200 \mu M$ 4-nitrophenol (Sigma Chemical Co.) and the respective inhibitor or no inhibitor controls for $4 \mathrm{~h}$. Hydroxylation of 4-nitrophenol has been used as a specific substrate for CYP2E1 activity; however, CYP2A, CYP2C, and CYP3A have been shown to contribute to the hydroxylation of 4-nitrophenol to 4-nitrocatechol (Table 3). Formation of glucuronide-conjugated 4-nitrocatechol was used to assess UGT1A inhibition (Table 3). The conversion of 4-nitrophenol to 4-nitrocatechol was determined using a Spectra Max Plus plate reader (Molecular Devices Inc., Sunnyvale, CA) adapted from David et al. (1998). Incubated media was split into 2 tubes and combined with either $5 \%$ acetic acid and acetate buffer (measurement of unconjugated 4-nitrocatchol) or acetate buffer containing $50 \mathrm{U}$ of $\beta$-glucuronidase (to measure conjugated 4-nitrocatechol; Sigma Chemical Co.) and incubated for $90 \mathrm{~min}$ at $21^{\circ} \mathrm{C}$ (adapted from Reinke and Moyer, 1985). Following the 90-min incubation, the solution was combined with sodium hydroxide $(5 \mathrm{M})$ and the absorbance was determined at $546 \mathrm{~nm}$ against a standard curve of 4-nitrocatechol $(0-250 \mu M)$. Total 4-nitrocatechol formation (hydroxylation of 4-nitrophenol) is reported as the sum of conjugated and unconjugated metabolites (Reinke and Moyer, 1985). In a preliminary experiment, the rate of 4-nitrocatechol production was determined to be linear over $4 \mathrm{~h}$. The glucuronide conjugate is reported as the amount of 4-nitrocatechol measured following the 90-min exposure to $\beta$-glucuronidase. Conjugated and unconjugated 4 -nitrocatechol is reported as nanomoles per hour times $10^{6}$ cells.

Measurement of phenol red glucuronidation was adapted from Behnia et al. (2000) and used to assess UGT1B inhibition (Table 3). The day before experimentation, growth media was replaced with serum-free media containing phenol red. The media was replaced $24 \mathrm{~h}$ later with serum-free media containing phenol red with the addition of no inhibitor or enzyme inhibitor for $6 \mathrm{~h}$. Incubated media was combined with $5 \%$ acetic acid and acetate buffer or acetate buffer containing 100 $\mathrm{U}$ of $\beta$-glucuronidase and incubated for $3 \mathrm{~h}$ at $37^{\circ} \mathrm{C}$.
After the 3-h incubation, the solution was combined with $1 M$ glycine buffer and the absorbance was determined at $546 \mathrm{~nm}$. The extinction coefficient for phenol red $(8,450 \mathrm{~L} / \mathrm{mol}$ per $\mathrm{cm})$ was used to express the rate of phenol red glucuronidation in picomoles per hour times $10^{6}$ cells. In a preliminary experiment, the rate of phenol red glucuronidation was determined to be linear over $8 \mathrm{~h}$.

\section{Cellular Fractionation and Enzymatic Activity}

To determine inhibitor specificity (Table 3 ) in bovine liver, frozen tissue was fractionated for the following experiments. Dairy cow frozen liver samples $(\mathrm{n}=4)$ were submerged in phosphate buffer and homogenized using a Dounce homogenizer. Homogenized tissue was centrifuged at 10,000 $\times g$ for 10 min and supernatant was collected for experiments using cytoplasmic fractions. Microsomes were collected and concentrated using differential centrifugation techniques (Nelson et al., 2001). Homogenized tissue was centrifuged at $10,000 \times g$ for 10 min. Pellets were discarded and the supernatants were centrifuged at 100,000 $\times g$ for $60 \mathrm{~min}$. The microsomal pellets were resuspended in phosphate buffer containing 20\% glycerol. Cytoplasmic and microsomal protein was determined using a Coomassie Plus (Bradford) protein assay following the manufacturer's protocol (Thermo Scientific, Rockford, IL) and used to standardize AKR1C, CYP2C, and CYP3A activity. Aldo-keto reductase $1 \mathrm{C}$ activity was determined in cytoplasmic cellular fractions using the specific substrate, 1-acenapthenol (Sigma Chemical Co.), following the methods of Savlík et al. (2007) and Palackal et al. (2002). Briefly, AKR1C enzymatic reactions contained 150 to $650 \mu \mathrm{g}$ of cytoplasmic protein, $250 \mu M$ 1-acenapthenol, and 500 $\mu M$ NADP. The 1-acenapthenol-dependent reduction of NADP was standardized using the amount of cytoplasmic protein. Cytochrome P450 2C, CYP3A, and CYP reductase activity was assessed on frozen liver samples following our previously published protocol (Lemley et al., 2010). Cytochrome P450 2C activity was measured as the non-ketoconazole-inhibitable, omeprazole- 
Table 4. Percentage progesterone decay inhibited in a preliminary experiment ${ }^{1}$

\begin{tabular}{|c|c|c|c|c|c|c|c|c|}
\hline \multirow[b]{2}{*}{ Inhibitor } & \multicolumn{4}{|c|}{ Pig } & \multicolumn{4}{|c|}{ Cow } \\
\hline & Decay, $\%$ & Inhibited, \% & SEM & $P$-value & Decay, \% & Inhibited, \% & SEM & $P$-value \\
\hline None & 54.8 & & 7.4 & & 49.6 & & 8.0 & \\
\hline Ticlopidine & 28.7 & 47.6 & 4.5 & $<0.001$ & 31.0 & 37.5 & 5.5 & 0.081 \\
\hline Diltiazem & 47.3 & 13.6 & 3.9 & 0.489 & 43.6 & 12.1 & 2.9 & 0.931 \\
\hline Naproxen & 45.6 & 16.8 & 5.2 & 0.249 & 35.1 & 29.3 & 2.4 & 0.248 \\
\hline Dicumarol & 37.7 & 31.1 & 1.7 & 0.003 & 36.9 & 25.5 & 3.2 & 0.384 \\
\hline Curcumin & 13.7 & 75.0 & 4.1 & $<0.001$ & 12.9 & 73.9 & 0.5 & $<0.001$ \\
\hline
\end{tabular}

${ }^{1}$ Progesterone inactivation was determined in duplicate in hepatic cultures from 2 pigs and 2 dairy cows.

dependent oxidation of NADPH. Cytochrome P450 $3 \mathrm{~A}$ activity was measured as the nifedipine-dependent oxidation of NADPH. Cytochrome P450 reductase activity was determined using a cytochrome c reductase assay kit (Sigma Chemical Co.). Cytochrome P450 reductase acts a coenzyme, which functions as an electron carrier by transferring electrons from NADPH to all CYP isozymes, and inhibiting CYP reductase would decrease all CYP activity. Aldo-keto reductase 1C, CYP2C, CYP3A, and CYP reductase activity was determined after a 30 -min preincubation with enzyme inhibitors. Stock solutions were prepared according to the cell culture experiments. All inhibitors were diluted in phosphate buffer, substrates, and cellular fractions to reach a final concentration of 50 or $150 \mu M$ ticlopidine, 50 or $150 \mu M$ diltiazem, 20 or $60 \mu M$ curcumin, 20 or $60 \mu M$ dicumarol, and 50 or $150 \mu M$ naproxen, which represents $1 \times$ or $3 \times$ inhibitor concentrations, respectively, compared with the cell culture experiments. All solutions were added to UV star 96-well plates (PGC Scientifics, Frederick, MD), and the oxidation of NADPH or reduction of NADP was determined by measuring the amount of light absorbed at $340 \mathrm{~nm}$ for 5 min. The extinction coefficient for NADPH $(6,220 \mathrm{~L} /$ mol $\times \mathrm{cm})$ was used to calculate the rate of oxidized NADPH or reduced NADP in picomoles per minute per milligram of protein.

\section{Statistical Analysis}

For the cell culture experiments, the effects of inhibitor on cell viability, progesterone inactivation, 4-nitrophenol metabolism, and phenol red metabolism were tested with the MIXED procedure of SAS (version 9.1, SAS Institute Inc., Cary, NC). The random statement included cow $(\mathrm{n}=6)$. The model statement included replicate $(\mathrm{n}=3)$ to assess variation attributed to the day of experimentation. Means were separated using the PDIFF option of the LSMEANS statement. For the cytoplasmic and microsomal assays, the effects of inhibitor on enzyme activity were tested using the MIXED procedure of SAS and means were separated using the PDIFF option of the LSMEANS statement. Least squares means and standard errors of the mean are reported. Statistical significance was declared at $P$ $<0.05$.

\section{RESULTS \\ Cell Dissociation and Morphology}

Cell yields averaged $40.8 \times 10^{6}$ live cells/g of liver tissue, with a cell viability of $83 \%$ (Table 1 ). Based on cellular morphology, approximately $60 \%$ of the cultured cells had a fibroblastic-like appearance, which stained positive for actin (yellow arrows; Figure 2A, B, and C). Approximately $25 \%$ of the cultured cells retained the ability to synthesize albumin, which is specific for viable hepatocytes (white arrows; Figure $2 \mathrm{~A}, \mathrm{~B}$, and C), whereas the remainder, approximately $15 \%$, did not stain positive for actin or albumin (red arrows; Figure $2 \mathrm{~A}$ and $\mathrm{B}$ ). The negative control did not show appreciable amounts of red or green fluorescence (Figure 2D).

\section{Progesterone Inactivation and Cell Viability}

In a preliminary experiment, pig and dairy cow hepatic cell cultures were challenged with varying concentrations of inhibitors for different amounts of time in the presence of $5 \mathrm{ng} / \mathrm{mL}$ of progesterone to determine cell viability and to estimate the optimal time to study progesterone inactivation following progesterone exposure. Some inhibitors and all inhibitor combinations were excluded from the study because of a decrease in cell viability following exposure. Cell viability in porcine hepatic cultures exposed to no inhibitor, $50 \mu \mathrm{M}$ ticlopidine, $50 \mu M$ diltiazem, $20 \mu M$ curcumin, $20 \mu M$ dicumarol, or $50 \mu M$ naproxen was not significantly different and averaged $79 \pm 1 \%$. Similarly, cell viability in bovine hepatic cultures exposed to the same inhibitor concentrations was not significantly different and averaged $83 \pm 1 \%$. Progesterone inactivation in controls (no inhibitor) was approximately $50 \%$ after $1 \mathrm{~h}$ of culture with $5 \mathrm{ng} / \mathrm{mL}$ of progesterone (Table 4). In 

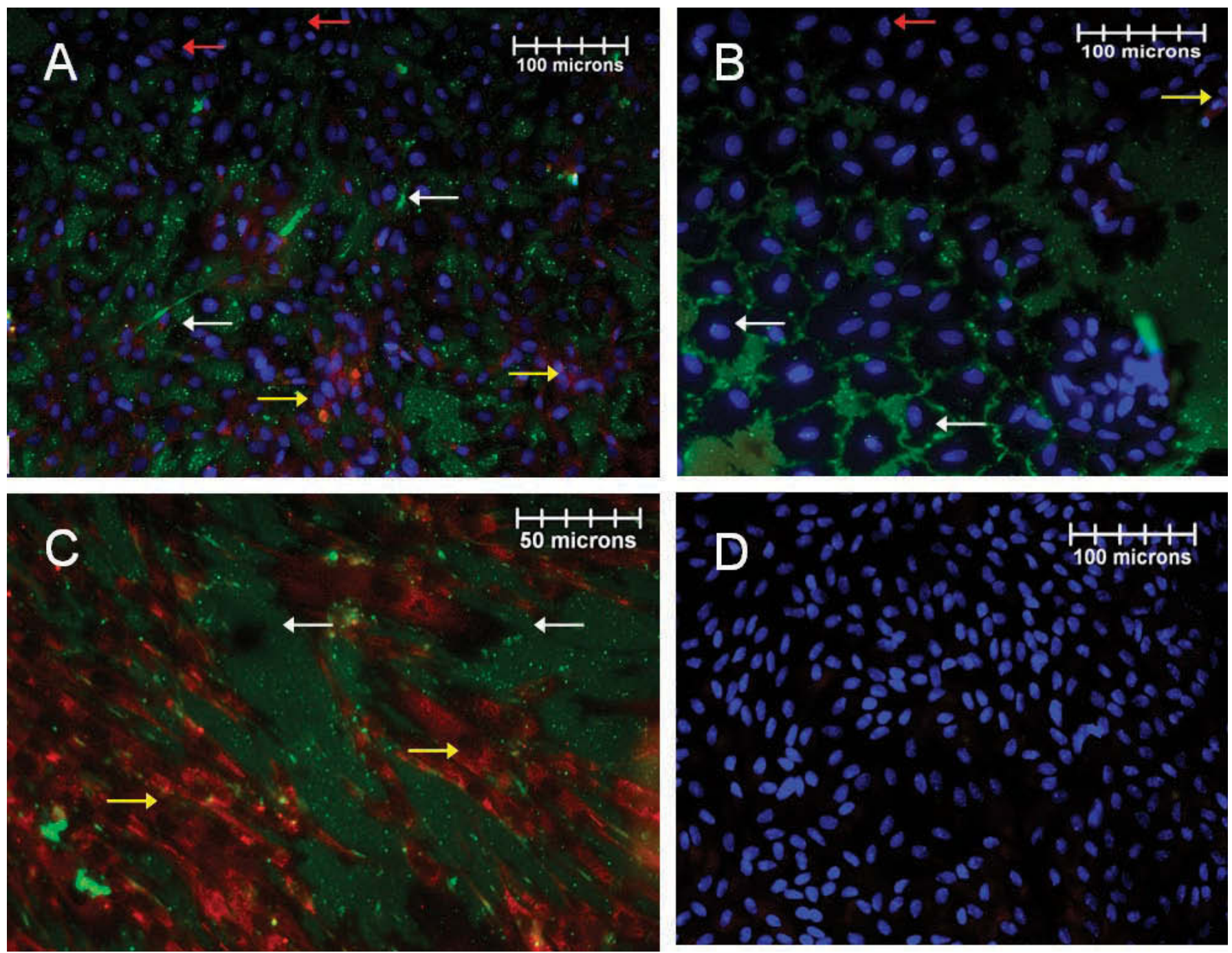

Figure 2. Immunofluorescence images from dairy cow hepatic cell cultures. Cells were stained for albumin (green, rabbit polyclonal antisheep IgG conjugated with fluorescein-5-isothiocyanate), actin (red, goat polyclonal anti-mouse IgG conjugated with phycoerythrin), and nuclei (blue, Hoechst). Images A and B were stained for albumin, actin, and nuclei. Image $\mathrm{C}$ was stained for albumin and actin. Image D (negative control) was incubated with the secondary antibodies conjugated to fluorophore and nuclei were stained with Hoechst. White, yellow, and red arrows highlight cell populations that were positive for albumin, actin, or neither, respectively.

both porcine and bovine hepatic cultures, treatment with $20 \mu M$ curcumin resulted in the greatest reduction in progesterone inactivation (75 and $74 \%$, respectively). In porcine hepatic cultures, ticlopidine and dicumarol inhibited progesterone inactivation by 48 and $31 \%$, respectively (Table 4 ).

Liver biopsies were taken from 6 lactating dairy cows (Table 1). Similar to the preliminary experiments, enzyme inhibitors did not alter $(P>0.50)$ cell viability, which averaged $84 \pm 1 \%$. After a 1 -h culture with 5 $\mathrm{ng} / \mathrm{mL}$ of progesterone, approximately $50 \%$ of the progesterone had been inactivated (Figure 3). All of the enzyme inhibitor treatments caused a reduction $(P$ $<0.01)$ in progesterone inactivation compared with controls (Figure 3). Similar to the preliminary experiments, treatment with $20 \mu M$ curcumin inhibited progesterone inactivation by $77 \%$ (Figure 3). Ticlopidine or naproxen treatment inhibited progesterone decay by approximately $40 \%$ compared with control cells, whereas diltiazem or dicumarol treatment inhibited progesterone inactivation by 15 or $23 \%$, respectively (Figure 3).

\section{Metabolism of 4-Nitrophenol and Phenol Red in Intact Cells}

Hydroxylation of 4-nitrophenol to 4-nitrocatechol was inhibited by approximately $65 \%$ in cells treated 


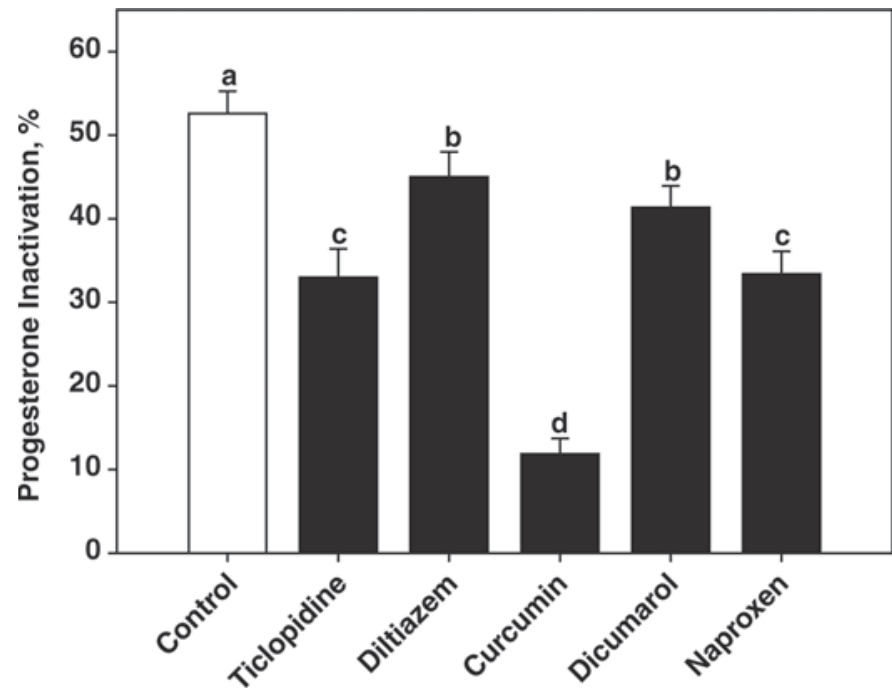

Figure 3. Progesterone inactivation in dairy cow hepatic cell cultures after a 4 -h preincubation with no inhibitor (control), ticlopidine, diltiazem, curcumin, dicumarol, and naproxen followed by a 1-h challenge with $5 \mathrm{ng} / \mathrm{mL}$ of progesterone plus inhibitor $(\mathrm{n}=6)$. Data are represented as mean \pm SEM, and different letters depict treatment differences $(P<0.01)$.

with ticlopidine or curcumin (Figure 4A). Diltiazem inhibited 4-nitrocatechol formation by $45 \%$, whereas naproxen caused a $30 \%$ reduction (Figure 4A). Dicumarol treatment had no effect on 4-nitrophenol hydroxylation. Glucuronidation of 4-nitrocatechol (Figure 4B) in intact cells was not affected by treatment with ticlopidine or diltiazem. The formation of 4-nitrocatechol glucuronide metabolites was inhibited by treatment with curcumin, dicumarol, or naproxen (Figure 4B). Glucuronidation of phenol red (Figure 4C) was not affected by treatment with ticlopidine; however, diltiazem caused a $17 \%$ reduction $(P=0.04)$ compared with controls. The formation of phenol red glucuronide metabolites was significantly inhibited by treatment with curcumin, dicumarol, or naproxen (Figure 4C).

\section{$A K R$ and CYP Activity in Cellular Fractions}

Curcumin, dicumarol, and naproxen treatments inhibited AKR1C activity in cytoplasmic preparations (Figure 5A). At either concentration, curcumin or naproxen caused an average decrease in AKR1C activity of 70 or $26 \%$, respectively. An effect of inhibitor concentration was observed after treatment with ticlopidine or dicumarol (Figure 5A). Aldo-keto reductase $1 \mathrm{C}$ activity was inhibited by $46 \%$ after treatment with $20 \mu M$ dicumarol, whereas $60 \mu M$ dicumarol caused a $69 \%$ reduction. Cells treated with $50 \mu M$ ticlopidine had similar AKR1C activity compared with controls; however, treatment with $150 \mu M$ ticlopidine caused
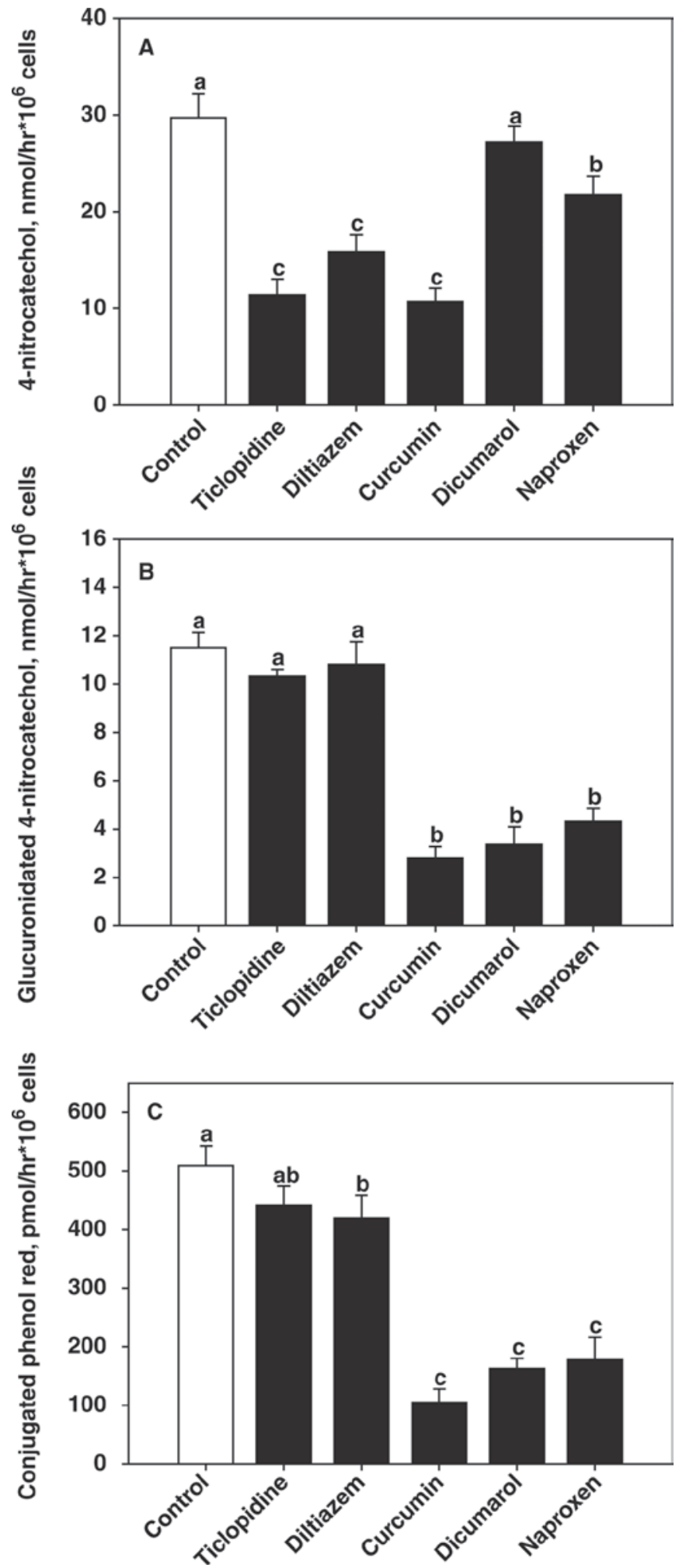

Figure 4. (A) 4-Nitrocatechol production, (B) 4-nitrocatechol glucuronidation, and $(\mathrm{C})$ phenol red glucuronidation in dairy cow hepatic cell cultures after a 4-h preincubation with no inhibitor (control), ticlopidine, diltiazem, curcumin, dicumarol, and naproxen $(\mathrm{n}=6)$. Data are represented as mean \pm SEM, and different letters depict treatment differences $(P<0.05)$. 

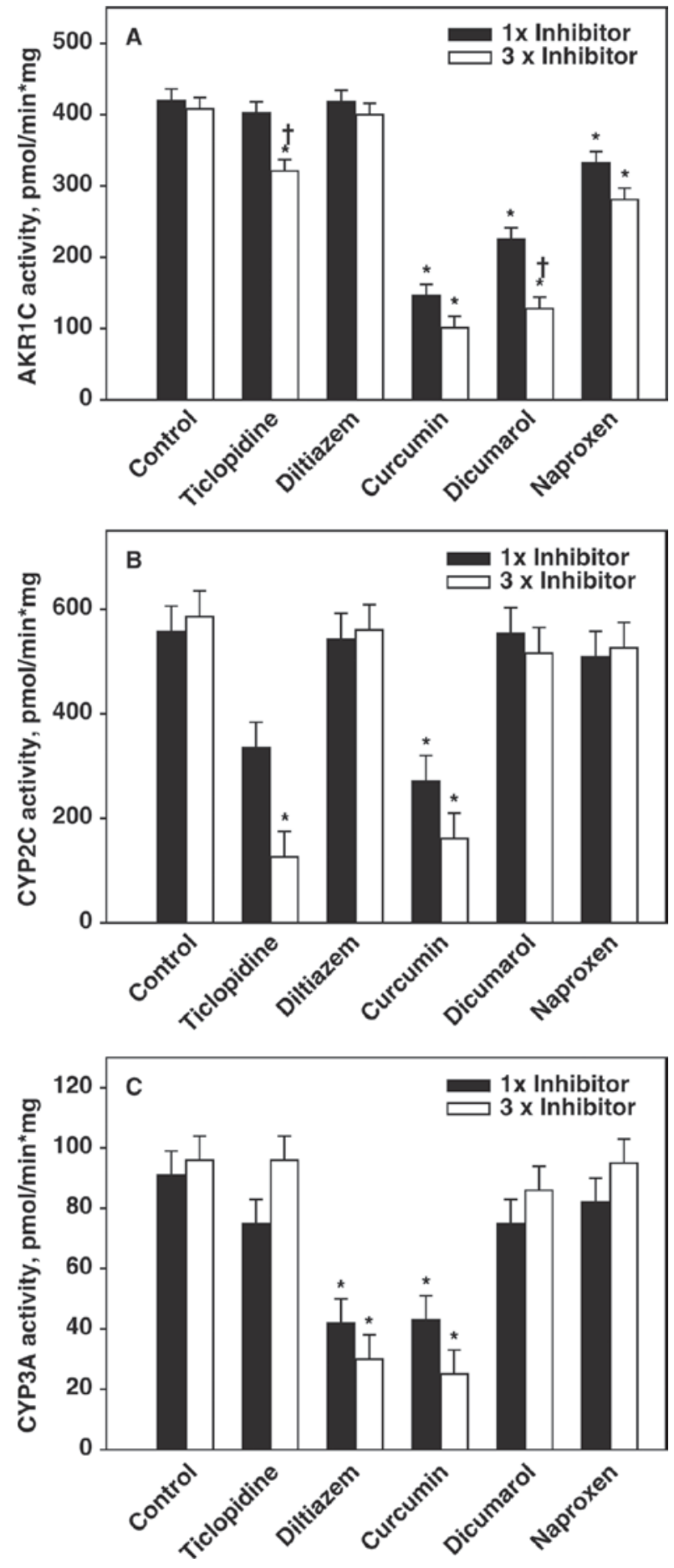

Figure 5. (A) Aldo-keto reductase 1C subfamily (AKR1C), (B) cytochrome P450 2C (CYP2C), and (C) cytochrome P450 3A (CYP3A) activity after a 30-min challenge with no inhibitor (control), ticlopidine, diltiazem, curcumin, dicumarol, and naproxen $(\mathrm{n}=4)$. Values are expressed as picomoles of NADP reduced per minute per milligram of cytoplasmic protein (AKR1C) or picomoles of NADPH oxidized per minute per milligram of microsomal protein (CYP2C, CYP3A). Asterisk $(*)$ represents a significant difference $(P<0.05)$ from controls. Cross $(\dagger)$ represents a significant difference $(P<0.05)$ within treatment attributed to inhibitor concentration $(1 \times$ or $3 \times$ inhibitor concentration compared with cell culture experiments). a $21 \%$ reduction in AKR1C activity. Cytochrome P450 2C activity was inhibited by either concentration of curcumin, with a reduction of 51 and $76 \%$ in cells treated with 20 or $60 \mu M$ curcumin, respectively (Figure 5B). The highest concentration of ticlopidine $(150 \mu M)$ caused a $78 \%$ reduction in CYP2C activity, whereas cells treated with $50 \mu M$ ticlopidine had $40 \%$ lower CYP2C activity that failed to reach statistical significance compared with controls $(P=0.09$; Figure 5B). Cytochrome P4503A activity was inhibited by approximately $60 \%$ after treatment with diltiazem or curcumin (Figure 5C). Ticlopidine, dicumarol, and naproxen did not affect CYP3A activity at any of the concentrations tested (Figure 5C). Microsomal CYP reductase activity was not different between enzyme inhibitor treatments $(P=0.09)$ and averaged $9.96 \pm$ $0.17 \mathrm{mU} / \mathrm{mg}$ of protein.

\section{DISCUSSION}

Primary cell cultures contained a mixed population of hepatic cells, with approximately $60 \%$ of the population having a fibroblast-like morphological appearance, which stained positive for actin. These populations represent nonparenchymal hepatic stellate cells, which have been shown to proliferate after injury to the liver and during nonpurified cell culture experiments (Mashimo et al., 1999). Hepatocytes have been shown to deteriorate structurally and lose albumin synthesizing abilities in primary cell culture preparations (van Zijl and Mikulits, 2010). The presence of positive albumin staining represents normal hepatic function and viable hepatocytes within our culture system (Spotorno et al., 2006). Under the current culture conditions, approximately $15 \%$ of the cell population did not stain positive for actin or albumin and may represent Kupffer or endothelial cells. In addition, endothelial cells become quiescent in the presence of proliferating stellate cells (van Zijl and Mikulits, 2010), which may explain the lower percentage of cells that were not positive for either albumin or actin.

The loses of albumin synthesis in primary hepatocyte cell cultures usually results in a concomitant decrease or no change in CYP or AKR expression and activity; furthermore, no in vitro model truly recapitulates the responses observed in vivo. In the current study, hepatic cell cultures were metabolically active and inactivating progesterone at a fast rate (50\% after a 1-h exposure) in cell cultures. In addition, specific inhibitors toward CYP2C, CYP3A, and AKR1C caused a decrease in progesterone inactivation. David et al. (1998) found stable protein expression and activity for CYP1A1, CYP3A4, and CYP2E1 for 4 or $5 \mathrm{~d}$ of experimentation in primary human hepatic cell cultures. In primary porcine hepatic 
cell cultures, diazepam metabolism (CYP enzymes) and phenol red glucuronidation (UGT enzymes) were stable for $8 \mathrm{~d}$ of culture (Behnia et al., 2000). In the current study, metabolism of 4-nitrophenol and phenol red were observed after $14 \mathrm{~d}$ of culture and comparable with these previous reports in human and porcine cell cultures (David et al., 1998; Behnia et al., 2000), suggesting stable expression of CYP and UGT enzymes throughout the study period. However, in 4-wk-old bovine hepatocyte cell cultures, CYP activity, measured as 7-ethoxycoumarin hydroxylation, decreased to $90 \%$ of 1-d-old cultures (Spotorno et al., 2006). Moreover, induction or depression of these enzymes in vitro may alter the relative contributions to total progesterone inactivation compared with in vivo conditions.

In sheep liver microsomal preparations, CYP2C and CYP3A metabolized progesterone to 21-hydroxyprogesterone (deoxycorticosterone) and $6 \beta$-hydroxyprogesterone at a rate of 270 or $430 \mathrm{pmol} /$ min per milligram of microsomal protein, respectively (Murray, 1991, 1992). The total microsomal contributions to progesterone inactivation were determined to be approximately $25 \%$ for CYP2C and approximately $55 \%$ for CYP3A in sheep. Conversely, we found a greater contribution from the CYP2C enzymes, which contributed $40 \%$, whereas CYP3A contributed only $15 \%$ to total progesterone inactivation in the lactating dairy cow. The higher contribution from the CYP2C inhibitor (ticlopidine) may be attributed to its inhibitory effects on AKR1C enzymes. In cytoplasmic preparations treated with excessive concentrations of ticlopidine, we found a $21 \%$ reduction in AKR1C activity. However, similar to our observations in vitro, recent reports in the dairy cow showed a negative correlation of in vivo endogenous progesterone concentrations with CYP2C activity, whereas CYP3A activity was not associated with endogenous progesterone concentrations (Sá Filho et al., 2009). In addition, decreased activity of CYP2C and CYP3A has been associated with lowered progesterone clearance in dairy cows, sheep, and a mouse hepatocyte cell-line (Lemley et al., 2008, 2009, 2010). However, to our knowledge no report has examined the relative contributions of each enzyme to progesterone inactivation in vitro.

The use of intact cell cultures in the current study allowed us to determine contributions from cytoplasmic enzymes, specifically AKR1C. In mouse liver or kidney, 20 $\alpha$-hydroxyprogesterone formation (AKR1C activity) occurred at a rate of approximately 800 or $400 \mathrm{pmol} / \mathrm{min}$ per milligram of cytoplasmic protein, respectively (Imamura et al., 2007). In the current study, AKR1C inhibition caused a $40 \%$ decrease in progesterone catabolism after a 1-h challenge with $5 \mathrm{ng} / \mathrm{mL}$ of progesterone; however, treatment with the selective
AKR inhibitor (naproxen) showed a significant reduction in 4-nitrocatechol and phenol red glucuronidation (UGT enzyme family). We originally hypothesized that inhibition of UGT enzymes would not affect the rate of progesterone inactivation; however, a buildup of hydroxysteroid metabolites after inhibiting UGT enzymes may lead to a lower rate of phase I progesterone inactivation. Moreover, the $40 \%$ inhibition in progesterone inactivation after treating cells with the AKR1C inhibitor (naproxen) may be a result of decreased glucuronidation in these cultures.

The current study focused on progesterone inactivation in early-lactation dairy cows. Szotáková et al. (2004) examined protein expression and activity for CYP, AKR, and UGT enzymes in pig, cattle, goat, and sheep. Interspecies differences in CYP and AKR activity were found for all of the species tested. The conjugation of 4-nitrophenol (UGT activity) was highest in ovine microsomes and similar among caprine, bovine, and porcine (Szotáková et al., 2004). From these studies, Szotáková et al. (2004) concluded that biotransformation of veterinary pharmaceuticals in domesticated species should be consistently tested on target species and not extrapolated from one species to another. Giantin et al. (2008) examined expression and activity for CYP and UGT enzymes in males of 3 different breeds of cattle (Charolais, Piedmontese, and Blonde d'Aquitaine). In Charolais cattle, CYP activity was not correlated with CYP mRNA expression, which may be attributed to significant transcriptional or posttranslational modifications that are not apparent in the other breeds tested (Giantin et al., 2008). In the rat, hepatic protein expression and CYP activity were consistently lower in pregnant versus nonpregnant age-matched controls (Dean and Stock, 1975; He et al., 2005). The differences in enzyme expression across species, breed, and physiological state (pregnant, cycling, or lactating) illustrates a necessity for more studies in the lactating Holstein, which could be drastically different from common laboratory species, other breeds of cattle, or nonlactating cows.

\section{CONCLUSIONS}

Several studies have focused on progesterone production during the estrous cycle, and various cellular mechanisms and models have been elucidated in controlling luteal function (Niswender et al., 2000; Schams and Berisha, 2004), whereas a paucity of information exists on the relative contributions of CYP and AKR to total progesterone inactivation. Recently, our laboratory showed a tendency for a longer half-life of progesterone in dairy cows fed an insulin-stimulating diet that decreased the activity of CYP2C and CYP3A (Lemley 
et al., 2010). From the current data set, we conclude that the enzymes CYP2C, AKR1C, and CYP3A are the major contributors to hepatic inactivation of progesterone in the lactating dairy cow (in order of highest to lowest activity). We could not distinguish between AKR1C and UGT enzymes because of similar inhibition, and future work elucidating the specific isozymes in the dairy cow could lead to a better understanding of these pathways. Moreover, determining the specific isozymes and their contributions to steroid clearance will allow researchers to characterize these pathways during various physiological states in vivo.

\section{REFERENCES}

Anzenbacher, P., and E. Anzenbacherova. 2001. Cytochrome P450 and metabolism of xenobiotics. Cell. Mol. Life Sci. 58:737-747.

Barski, O. A., S. M. Tipparaju, and A. Bhatnagar. 2008. The aldoketo reductase superfamily and its role in drug metabolism and detoxification. Drug Metab. Rev. 40:553-624.

Basu, N. K., M. Kovarova, A. Garza, S. Kubota, T. Saha, P. S. Mitra, R. Banerjee, J. Rivera, and I. S. Owens. 2005. Phosphorylation of a UDP-glucuronosyltransferase regulates substrate specificity. Proc. Natl. Acad. Sci. USA 102:6285-6290.

Behnia, K., S. Bhatia, N. Jastromb, U. Balis, S. Sullivan, M. Yarmush, and M. Toner. 2000. Xenobiotic metabolism by cultured primary porcine hepatocytes. Tissue Eng. 6:467-479.

Bowalgaha, K., D. J. Elliot, P. I. Mackenzie, K. M. Knights, and J. O. Miners. 2007. The glucuronidation of $\Delta^{4}-3$-keto C19- and C21-hydroxysteroids by human liver microsomal and recombinant UDP-glucuronosyltransferases (UGTs): $6 \alpha$ and 21 hydroxyprogesteorne are selective substrates for UGT2B7. Drug Metab. Dispos. 35:363-370.

Chagas, L. M., J. J. Bass, D. Blache, C. R. Burke, J. K. Kay, D. R. Lindsay, M. C. Lucy, G. B. Martin, S. Meier, F. M. Rhodes, J. R. Roche, W. W. Thatcher, and R. Webb. 2007. Invited review: New perspectives on the roles of nutrition and metabolic priorities in the subfertility of high-producing dairy cows. J. Dairy Sci. 90:4022-4032.

David, P., C. Viollon, E. Alexandre, A. Azimzadeh, L. Nicod, P. Wolf, D. Jaech, K. Boudjema, and L. Richert. 1998. Metabolic capacities in cultured human hepatocytes obtained by a new isolating procedure from non-wedge small liver biopsies. Hum. Exp. Toxicol. $17: 544-553$.

Dean, M. E., and B. H. Stock. 1975. Hepatic microsomal metabolism of drugs during pregnancy in the rat. Drug Metab. Dispos. $3: 325-331$

Emmison, N., L. Agius, and V. A. Zammit. 1991. Regulation of fatty acid metabolism and gluconeogenesis by growth hormone and insulin in sheep hepatocyte cultures. Biochem. J. 274:21-26.

Giantin, M., M. Carletti, F. Capolongo, S. Pegolo, R. M. Lopparelli, F. Gusson, C. Nebbia, M. Canteillo, P. Martin, T. Pineau, and M. Dacasto. 2008. Effect of breed upon cytochromes P450 and phase II enzyme expression in cattle liver. Drug Metab. Dispos. 36:885-893.

He, X. J., N. Ejiri, H. Nakayama, and K. Doi. 2005. Effects of pregnancy on CYPs protein expression in rat liver. Exp. Mol. Pathol. $78: 64-70$

Imamura, Y., M. Ohtaguro, and H. Shimada. 2007. Several distinct enzymes catalyze $20 \alpha$-hydroxysteroid dehydrogenase activity in mouse liver and kidney. J. Steroid Biochem. Mol. Biol. 107:120126.

Jones, D. R., J. C. Gorski, M. A. Hamman, B. S. Mayhew, S. Rider, and S. D. Hall. 1999. Diltiazem inhibition of cytochrome P-450 3A activity is due to metabolite intermediate complex formation. J. Pharmacol. Exp. Ther. 290:1116-1125.
Kabututu, Z., M. Manin, J. C. Pointud, T. Maruyama, N. Nagata, S. Lambert, A. M. Lefrancois-Martinez, A. Martinez, and Y. Urade. 2009. Prostaglandin F2alpha synthase activites of aldo-keto reductase 1B1, 1B3 and 1B7. J. Biochem. 145:161-168.

Ko, J. W., Z. Desta, N. V. Soukhova, T. Tracy, and D. A. Flockhart. 2000. In vitro inhibition of the cytochrome P450 (CYP450) system by the antiplatelet drug ticlopidine: Potent effect on CYP2C19 and CYP2D6. Br. J. Clin. Pharmacol. 49:343-351.

Lemley, C. O., J. M. Koch, K. P. Blemings, K. M. Krause, and M. E. Wilson. 2008. Concomitant changes in progesterone catabolic enzymes, cytochrome P450 2C and 3A, with plasma insulin concentrations in ewes supplemented with sodium acetate or sodium propionate. Animal 2:1223-1229.

Lemley, C. O., J. M. Koch, K. P. Blemings, and M. E. Wilson. 2009. Alterations in progesterone catabolic enzymes, CYP2C and CY$\mathrm{P} 3 \mathrm{~A}$, in hepatocytes challenged with insulin and glucagon. $\mathrm{J}$. Anim. Vet. Advances 8:39-46.

Lemley, C. O., T. A. Wilmoth, L. R. Tager, K. M. Krause, and M. E. Wilson. 2010. Effect of a high cornstarch diet on hepatic cytochrome P450 2C and 3A activity and progesterone half-life in dairy cows. J. Dairy Sci. 93:1012-1021.

Leroy, J. L. M. R., A. Van Soom, G. Opsomer, I. G. F. Goovaerts, and P. E. J. Bols. 2008. Reduced fertility in high-yielding dairy cows: Are the oocyte and embryo in danger? Part II. Reprod. Domest. Anim. 43:623-632.

Mashimo, Y., S. Mochida, M. Inao, M. Yamaoka, S. Nagoshi, A. Matsui, and K. Fujiwara. 1999. Decreased expression of smooth muscle $\alpha$ actin in activated rat hepatic stellate cells at the S-phase of the cell cycle in vitro. Hepatol. Res. 15:22-31.

Miller, H. M., G. R. Foxcroft, J. Squires, and F. X. Aherne. 1999. The effects of feed intake and body fatness on progesterone metabolism in ovariectomized gilts. J. Anim. Sci. 77:3253-3261.

Murray, M. 1991. Microsomal cytochrome P450-dependent steroid metabolism in male sheep liver. Quantitative importance of $6 \beta$-hydroxylation and evidence for the involvement of a P450 from the IIIA subfamily in the pathway. J. Steroid Biochem. Mol. Biol. 38:611-619.

Murray, M. 1992. Participation of a cytochrome P450 enzyme from the 2C subfamily in progesterone 21-hydroxylation in sheep liver. J. Steroid Biochem. Mol. Biol. 43:591-593.

Nakajima, M., N. Sakata, N. Ohashi, T. Kume, and T. Yokoi. 2002. Involvement of multiple UDP-glucuronosyltransferase $1 \mathrm{~A}$ isoforms in glucuronidation of 5-(4'-hydroxyphenyl)5-phenylhydantoin in human liver microsomes. Drug Metab. Dispos. 30:1250-1256.

Nelson, A. C., W. Huang, and D. E. Moody. 2001. Variables in human liver microsome preparation: Impact on the kinetics of L-alphaacetylmethadol (LAAM) $N$-demethylation and dextromethorphan O-demethylation. Drug Metab. Dispos. 29:319-325.

Niswender, G. D., J. L. Juengel, P. J. Silva, M. K. Rollyson, and E. W. McIntush. 2000. Mechanisms controlling the function and life span of the corpus luteum. Physiol. Rev. 80:1-29.

Palackal, N. T., S. H. Lee, R. G. Harvey, I. A. Blair, and T. M. Penning. 2002. Activation of polycyclic aromatic hydrocarbon transdihydrodiol proximate carcinogens by human aldo-keto reductase (AKR1C) enzymes and their functional overexpression in human lung carcinoma (A549) cells. J. Biol. Chem. 277:24799-24808.

Parr, R. A., I. F. Davis, M. A. Miles, and T. J. Squires. 1993. Liver blood flow and metabolic clearance rate of progesterone in sheep. Res. Vet. Sci. 55:311-316.

Penning, T. M., M. E. Burczynski, J. M. Jez, C. Hung, H. Lin, H. Ma, M. Moore, N. Palackal, and K. Ratnam. 2000. Human $3 \alpha$-hydroxysteroid dehydrogenase isoforms (AKR1C1-AKR1C4) of the aldo-keto reductase superfamily: Functional plasticity and tissue distribution reveals roles in the inactivation and formation of male and female sex hormones. Biochem. J. 351:67-77.

Reinke, L. A., and M. J. Moyer. 1985. p-Nitrophenol hydroxylation: A microsomal oxidation which is highly inducible by ethanol. Drug Metab. Dispos. 13:548-552.

Rhinehart, J. D., M. J. Starbuck-Clemmer, J. A. Flores, R. A. Milvae, J. Yao, D. H. Poole, and E. K. Inskeep. 2009. Low peripheral pro- 
gesterone and late embryonic/early fetal loss in suckled beef and lactating dairy cows. Theriogenology 71:480-490.

Sá Filho, O. G., C. O. Lemley, M. E. Wilson, J. Hillegass, J. L. M. Vasconcelos, and W. R. Butler. 2009. Relationships between dry matter intake (DMI), plasma progesterone (P4), and liver catabolic enzymes in lactating dairy cows. J. Anim. Sci. 87(Suppl. 2):M229. (Abstr.)

Sangsritavong, S., D. K. Combs, R. Sartori, L. E. Armentano, and M. C. Wiltbank. 2002. High feed intake increases liver blood flow and metabolism of progesterone and estradiol-17 $\beta$ in dairy cattle. J. Dairy Sci. 85:2831-2842.

Savlík, M., L. Polackova, B. Szotáková, J. Lamka, J. Velik, and L. Skalova. 2007. Activities of biotransformation enzymes in pheasant (Phasianus colchicus) and their modulation by in vivo administration of mebendazole and flubendazole. Res. Vet. Sci. 83:20-26.

Schams, D., and B. Berisha. 2004. Regulation of corpus luteum function in cattle-An overview. Reprod. Domest. Anim. 39:241251.

Segura-Aguilar, J. E., V. Barreiro, and C. Lind. 1986. Dicoumarol-sensitive glucuronidation of benzo(a)pyrene metabolites in rat liver microsomes. Arch. Biochem. Biophys. 251:266-275.

Sheffel, C. E., B. R. Pratt, W. L. Ferrell, and E. K. Inskeep. 1982. Induced corpora lutea in the postpartum beef cow. II. Effects of treatment with progestogen and gonadotropins. J. Anim. Sci. 54:830-836.

Spotorno, V. G., A. Hidalgo, M. Barbich, A. Lorenti, and O. Zabal. 2006. Culture of bovine hepatocytes: A non-perfusion technique for cell isolation. Cytotechnology 51:51-56.

Szotáková, B., V. Baliharova, J. Lamka, E. Nozenova, V. Wsol, J. Velik, M. Machala, J. Neca, P. Soucek, S. Susova, and L. Skolova.
2004. Comparison of in vitro activities of biotransformation enzymes in pig, cattle, goat and sheep. Res. Vet. Sci. 76:43-51.

Thomford, P. J., and P. J. Dziuk. 1986. The influence of dose of phenobarbital and interval to measurement on concentration of liver enzymes in barrows and gilts. J. Anim. Sci. 63:1184-1190.

Turgeon, D., J. Carreir, S. Chouinard, and A. Belanger. 2003. Gulcuronidation activity of the UGT2B17 enzyme toward xenobiotics. Drug Metab. Dispos. 31:670-676.

van Zijl, F., and W. Mikulits. 2010. Hepatospheres: Three dimensiona cell cultures resemble physiological conditions of the liver. World J. Hepatol. 27:1-7.

Volak, L. P., S. Ghirmai, J. R. Cashman, and M. H. Court. 2008. Curcuminoids inhibit multiple human cytochromes P450 (CYP), UDP-glucuronosyltransferase (UGT), and sulfotransferase (SULT) enzymes, while piperine is a relatively selective CYP3A4 inhibitor. Drug Metab. Dispos. 36:1594-1605.

Waxman, D. J., D. P. Lapenson, T. Aoyama, H. V. Gelboin, F. J. Gonzalez, and K. Korzekwa. 1991. Steroid hormone hydroxylase specificities of eleven cDNA-expressed human cytochrome P450s. Arch. Biochem. Biophys. 290:160-166.

Yee, D. J., V. Balsanek, D. R. Bauman, T. M. Penning, and D. Sames. 2006. Fluorogenic metabolic probes for direct activity readout of redox enzymes: Selective measurement of human AKR1C2 in living cells. Proc. Natl. Acad. Sci. USA 103:13304-13309.

Zerilli, A., D. Ratanasavanh, D. Lucas, T. Goasduff, Y. Dreano, C. Menard, D. Picart, and F. Berthou. 1997. Both cytochromes P4502E and $3 \mathrm{~A}$ are involved in the O-hydroxylation of p-nitrophenol, a catalytic activity known to be specific for P4502E1. Chem. Res. Toxicol. 10:1205-1212. 